\title{
Diclofenac Epolamine Patch
}

National Cancer Institute

\section{Source}

National Cancer Institute. Diclofenac Epolamine Patch. NCI Thesaurus. Code C123266.

A topical patch containing the epolamine salt form of the nonsteroid anti-inflammatory drug (NSAID) diclofenac, with anti-inflammatory, anti-pyretic and analgesic activities. Upon topical application of the diclofenac epolamine patch to a specific area, the patch releases diclofenac epolamine into the skin. Diclofenac locally binds to cyclooxygenase isoforms 1 and 2 (COX-1 and -2). The inhibition of COX-2 by diclofenac prevents the COX2-mediated synthesis of proprostaglandins (PGs) and thereby locally relieves PGmediated pain, fever and inflammation. 